\section{KẾT LUẬN}

- Tất cả các bệnh nhân mất ngủ không thực tổn thể tâm tỳ hư đều đánh giá chất lượng giấc ngưở mức trung bình và kém với điểm PSQI trung bình 14,09 $\pm 2,22$ (điểm). Thời lượng giấc ngủ trung bình trong đêm 4,02 $\pm 0,53$ (giờ).

- Có mối liên quan giữa tình trạng mất ngủ không thực tổn với tuổi, nghề nghiệp, tình trạng hôn nhân và tiền sử sang chấn tâm lý.

\section{TÀI LIÊU THAM KHẢO}

1. Bộ môn Tâm thân - Trường Đại học Y Hà Nôi (2006). Rối loạn giấc ngủ không thực tổn. Giáo trình Tâm thần học dành cho bác sĩ đa khoa, NXB Y học, Hà Nội, 62-68.

2. Bộ môn $Y$ học cổ truyên - Hoc viện quân $Y$ (2008). Thất miên. Bệnh học nội khoa y học cổ

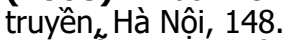

3. Nguyến Văn Tâm (2019). Nghiên cứu độc tính,tác dụng an thân trên thực nghiệm và điều trị mất ngủ không thực tổn trên lâm sàng của cao lỏng Dưỡng tâm an thần, Luận án tiến sĩ y học, Học viên Y Dược học cổ truyền Việt Nam.

4. Bố Y tế (2016). Quyết định số 3465/QĐ-BYT ngày $8 / 7 / 2016$ về viẹc ban hành bộ mã danh mục dùng chung trong khám bệnh, chữa bệnh và thanh toán bảo hiếm y tế. Phu lục: Danh muc bệnh theo ICD-10.

5. Wilson S, Nutt D (2008). Insomnia: guide to diagnosis and choice of treatment. Prescriber, 19 (8), 14-24.

6. Nguyê̂n Ngọc Đăng (2020). Đánh giá tác dụng điêu trị mất ngủ không thực tổn của viên nén İch khí an thần - HVY trên lâm sàng, Luận văn Thạc sĩ Y học, Hoc viên $Y$ Dược học cổ truyền Việt Nam.

7. Zhang M, Xu G, Luo C (2016). Qigong Yi Jinjing Promotes. Pulmonary Function, Physical Activity, Quality of Life and Emotion Regulation SelfEfficacy in Patients with Chronic Obstructive Pulmonary Disease: A Pilot Study. J Altern Complement Med, 22 (10), 12-14.

\title{
MỐI TƯƠNG QUAN GIỮA ĐĂC ĐIỂM KHÁNG THUỐC LÂM SÀNG, CÂN LÂM SÀNG CỦA BỆNH NHÂN LAO PHỔI TÁI PHÁT SAU 2 THÁNG ĐIỀU TRI
}

\section{TÓM TẮT}

Mục tiêu: Nghiên cứu mối tương quan giữa đăc điểm k̉ kháng thuốc với lâm sàng, cận lâm sàng của bệnh nhân lao phổi tái phát. Đối tượng và phương pháp: Nghiên cứu tiến cứu, mô tả cắt ngang, theo dõ̃i dọc trên 56 bệnh nhân lao phổi tái phát được đăng ký điều trị nội, ngoại trú tại Bệnh viện Phạm Ngọc Thạch, thành phố Hồ Chí Minh, trong thời gian 02 tháng. Kết quả: Các triệu chứng sốt, ho, khó thở gặp nhiêuu ở bệnh nhân đớn kháng. $X$ quang: Tổn thương mức độ hẹp BN lao phổi đa kháng cao hơn nhóm đớn kháng( $50 \%$ so với $25 \%$ ). Mức độ vửa và mức độ rộng chỉ gặp ở nhóm đơn kháng (kháng INH), khổng gặp ở nhóm đa kháng. Hang lao gặp $100 \%$ ở bệnh nhân đa kháng, đơn kháng gặp 25\%. Mức độ AF́B đờm liên quan tới đặc điểm kháng thuốc: Nhóm BN AFB (1+) có 7 BN nhóm kháng INH và $3 B N$ nhóm kháng RMP + INH. BN AFB $(2+)$ gặp nhóm kháng INH là $3 B N$ và nhóm kháng RMP + INH là 1 BN. BNAFB $(3+)$, gặp 2 BN ở nhóm kháng INH, và 1 BN ở nhóm kháng RMP + $\mathrm{INH}$. Nhóm BN kháng INH và kháng RMP + INH không có sự khác biệt về mối liên quan giữa các mức độ AFB (+). Kết luận: Lao phổi kháng thuốc có nhiều điểm khác biệt về lẩm sàng và cận lâm sàng so với lao phổi mới. Việc đánh giá mối tương quang giữa LS, CLS với đặc tính kháng thuốc của lao phổi có nhiêuu ý nghĩa

*Đại học Y khoa Phạm Ngọc Thạch

Chịu trách nhiệm chính: Đặng Vĩnh Hiệp

Email: hiepdv@pnt.edu.vn

Ngày nhận bài: 4/11/2020

Ngày phản biện khoa học: 20/12/2020

Ngày duyệt bài: 19/1/2021

\section{Đặng Vĩnh Hiệp*}

cho việc điều trị và dự phòng lao.

Từ khóa: Lao phổi kháng thuốc, lao đa kháng, lao đơn kháng, lao tái phát.

\section{SUMMARY}

\section{CORRELATION BETWEEN CLINICAL} PARACLINICAL WITH RESISTANT CHARACTERISTIC IN RECURRENT TB PATIENTS

Purpose: Research on the correlation between clinical, para - clinical with resistant characteristic in recurrent TB patients. Objective and method: $A$ prospective, cross-sectional study of 56 recurrent tuberculosis patients were diagnostic and treatment at Pham Ngoc Thach Hospital, Ho Chi Minh City in 2 months. Analysis of algorithm data base on statistical software and give results to research objectives. Results: Fever, cough and breathing difficulties symptoms were common in single drug- resistant TB patient. Chest $X$ ray findings:Mild level lesion in multi - resistant TB(approximate $50 \%$ ) was more commonly than single - resistant TB (approximate 25\%). Moderate and severe lesion were only in the single resistant TB. TB cavity was in all multi - resistant TB patient and about $25 \%$ in single - resistant TB patient. The correlation between positive AFP sputum smears results and resistant characteristic: Pulmonary TB patients with AFB smear-positive $(1+)$ include 7 patients with INH resistance and 3 patients with RMP + INH resistance. Pulmonary TB patients with AFB smear-positive $(2+)$ include 3 patients with INH resistance and 1 patient with RMP + INH resistance. Pulmonary TB patients with AFB smear-positive (3+) include 2 patients with INH resistance and 1 patient with RMP + INH resistance. Pulmonary 
TB patients with AFB smear-positive levels was not correlation in patients with INH resistance or patient with RMP + INH resistance. Conclusion: The clinical and paraclinical of resistant TB is different from the new TB. Research on the correlation between clinical and para - clinical of drug - resistance of TB is always treat and prevent significance.

Keywords: Drug - resistant tuberculosis, multi resistant tuberculosis, single - resistant tuberculosis, recurrent tuberculosis

\section{I. ĐẶT VẤN ĐỀ}

Tình hình dịch tễ bệnh lao phổi ở Việt Nam hiện còn rất cao với ước tính năm 2017 có khoảng 180.000 người mắc lao phổi mới và 12.000 người chết do Lao phổi. Tỷ lệ hiện mắc Lao phổi khoảng 289/100.000 dân. [1]. Bệnh lao tái phát cũng là một vấn đề cần được quan tâm. Số lượng bệnh nhẩn lao tái phát được phát hiện hàng năm chiếm tỷ lệ không nhỏ trong tổng số bệnh nhân lao được phát hiện. Theo thông báo của WHO năm 2005 tỷ lê bênh nhân lao phổi tái phát (LPTP) trong tổng số bệnh nhân lao được phát hiện của khu vực Châu Phi là $4,2 \%$, Chẩu Mỹ 6,1\%, Châu Âu 4,6\%, khu vực Trung Cận Đông 3,3\%, khu vực Đông Nam Châu Á 4,2\%, khu vực Tây Thái Bình Dương 8,7\%. So với lao phổi mới, LPTP tình trạng bệnh thường nặng hơn, tỷ lể kháng thuốc của vi khuẩn lao cao hơn, chẩn đoán bệnh gặp nhiều khó khăn và tỷ lệ điều trị khỏi thấp hơn [2]. Vì vậy chúng tôi tiến hành nghiên cứu đề tài "Nghiên cứu mối tương quan giữa đặc điểm kháng thuốc với lâm sàng, cận lâm sàng của bệnh nhân lao phổi tái phát sau 2 tháng điều trị"

\section{II. Đốl TƯợNG VÀ PHƯƠNG PHÁP NGHIÊN CứU}

2.1. Đối tương: Nghiên cứu được tiến hành trên 56 bệnh nhân lao phổi tái phát được đăng ký điều trị nội, ngoại trú tại Bệnh viện Phạm
Ngọc Thạch, thành phố Hồ Chí Minh, trong khoảng thời gian 02 tháng.

2.2. Phương pháp: Tiến cứu, mô tả cắt ngang, theo dõi dọc.

- Cỡ mẫu: lấy mẫu thuận tiện

- Quy trình nghiên cứu: Tiến hành thu thập các số liệu về lậm sàng, xét nghiệm và các dấu hiệu $X Q$ theo mẫu bệnh án có sẵn. Phân tích số liệu theo phần mềm thống kê thích hợp và đưa ra kết quả theo mục tiêu nghiên cứu.

\section{KẾT QUẢ NGHIÊN CỨU}

1. Đăc điểm đối tương nghiên cứu.Với 56 BN, tỷ lệ nam/nũ = 2,3(39/17). Lao phổi tái phát gặp ở tất cả các lứa tuổi, nam gặp nhiều ở lứa tuổi từ 18-70, nữ gặp nhiếu từ 18 tuổi đến 40.

Bảng 1. Đặc điểm kháng thuốc chống lao

\begin{tabular}{|c|c|c|}
\hline Mức độ kháng & $\mathbf{n}$ & $\mathbf{\%}$ \\
\hline Kháng INH & 12 & 21,42 \\
\hline Kháng RMP + INH & 5 & 8,93 \\
\hline Không kháng & 39 & 69,64 \\
\hline Tống & $\mathbf{5 6}$ & $\mathbf{1 0 0}$ \\
\hline
\end{tabular}

Nhận xét: Trong 56 BN có AFB (+) và xét nghiệm MGIT, GeneXpert dương tính, có $12 \mathrm{BN}$ kháng INH chiếm 21,42\%; có 5 BN kháng RMP + INH chiếm $8,93 \%$ và 39 BN không kháng, chiếm $69,64 \%$.

2. Mối liên quan giữa đặc điểm kháng thuốc với đặc điểm LS, cận lẩm sàng

Bảng 2. Liên quan giữa đặc điếm kháng thuốc với đặc điểm lâm sàng

\begin{tabular}{|c|c|c|c|c|}
\hline Triệu chứng & \multicolumn{2}{|c|}{ Đơn kháng } & \multicolumn{2}{c|}{ Đa kháng } \\
\cline { 2 - 5 } lâm sàng & $\mathbf{n}$ & $\mathbf{\%}$ & $\mathbf{n}$ & $\mathbf{\%}$ \\
\hline Sốt & 2 & 50 & 0 & 0 \\
\hline Ho & 0 & 0 & 1 & 50 \\
\hline Khó thở & 3 & 75 & 0 & 0 \\
\hline HC hang & 1 & 25 & 0 & 0 \\
\hline
\end{tabular}

Nhận xét: Các triệu chứng sốt, ho, khó thở gặp nhiều ở bệnh nhân đơn kháng.

Bảng 3. Liên quan giữa đặc điểm kháng thuốc với hinh ảnh Xquang

\begin{tabular}{|c|c|c|c|c|c|}
\hline \multirow{2}{*}{ Hình ảnh Xquang } & \multicolumn{2}{|c|}{ Kháng INH } & \multicolumn{2}{c|}{ Kháng RMP + INH } & \multirow{2}{*}{ p } \\
\cline { 2 - 5 } & $\mathrm{n}$ & $\%$ & $\mathrm{n}$ & $\%$ & 0.043 \\
\hline Mức độ hẹp & 1 & 25 & 1 & 50 & \\
\hline Mức độ̣ vừa & 2 & 50 & 0 & 0 & \\
\hline Mức độ̣ rộng & 1 & 25 & 0 & 0 & \\
\hline Hang lao & 1 & 25 & 2 & $100 \%$ & 0,038 \\
\hline
\end{tabular}

Nhận xét: - Tốn thương mức độ hẹp BN lao phối đa kháng cao hơn nhóm đơn kháng (50\% so với $25 \%$ ). Mức độ vừa và mức độ rộng chỉ gặp ở nhóm đơn kháng (kháng INH), không gặp ở nhóm đa kháng. - Hang lao gă̆p 100\% ở bệnh nhân đa kháng, đơn kháng gặp 25\%.

Bảng 4. Mức độ AFB đờm liên quan tới đặc điểm kháng thuốc

\begin{tabular}{|c|c|c|c|c|c|}
\hline \multirow{2}{*}{ XN AFB đờm } & \multicolumn{2}{|c|}{ Kháng INH (n=12) } & Kháng RMP + INH(n=5) & \multirow{2}{*}{ p } \\
\cline { 2 - 5 } & $\mathbf{n}$ & $\mathbf{\%}$ & $\mathbf{n}$ & $\mathbf{\%}$ & 0,324 \\
\hline AFB 1+ & 7 & 58,33 & 3 & 60,0 & 0,434 \\
\hline AFB 2+ & 3 & 25,0 & 1 & 20,0 & 0,434 \\
\hline AFB 3+ & 2 & 16,67 & 1 & 20,0 & 0.248 \\
\hline
\end{tabular}


Nhân xét:

- Nhóm BN AFB (1+) có 7 BN nhóm kháng INH và $3 \mathrm{BN}$ nhóm kháng RMP + INH.

- BN AFB (2+) gặp nhóm kháng INH là 3 BN và nhóm kháng RMP + INH là $1 \mathrm{BN}$.

- BN AFB (3+), gặp 2 BN ở nhóm kháng INH, và $1 \mathrm{BN}$ ở nhóm kháng RMP + INH.

- Nhóm BN kháng INH và kháng RMP + INH không có sự khác biệt về mối liên quan giữa các mức độ AFB (+).

\section{BÀN LUÂ̂N}

4.1. Đặc điểm chung về đôi tượng nghiên cứu. Tình hình dịch tễ lao kháng thuốc đang có diễn biến phức tạp và đã xuất hiện ở hầu hết các quốc gia. Năm 2015 trên toàn cầu ước tính tỷ lệ mắc lao đa kháng thuốc là 3,9\% trong số bệnh nhân mới và $21 \%$ trong số bệnh nhân điêu trị lại [3]. Trong năm 2015 ước tính có 580.000 người mới mắc lao kháng đa thuốc nhưng chỉ có 125.000 bệnh nhân (20\%) được đăng ký điêu trị. Trên toàn cầu tỷ lệ điều trị khỏi bệnh nhân kháng thuốc đạt $52 \%$ (số liệu năm 2013)[1]. Trong nghiên cứu của chúng tôi cho thấy Lao phổi tái phát gặp ở tất cả các lứa tuổi, nam gặp nhiêu ở lứa tuổi từ $18-70$, nữ gặp nhiều từ 18 tuổi đến 40. Theo Jamshid Gadoev (2017) trong 9358 bệnh nhân lao phổi tái phát, tác giả gặp tỷ lệ nam nhiều hơn nữ, cụ thể, nam chiếm $61 \%$ và nữ chiếm $39 \%$, so sánh giữa 2 giới khác biệt với $p<0,001$, trong đó độ tuổi hay gặp là trung niên từ 36-55 tuổi [4]. Điều này thường thây do nam giới thường nghiện rượu và thuốc lá, tuân thủ điều trị kém hơn phụ nữ.

Trong 56 bệnh nhân có $A F B(+)$ và xét nghiệm MGIT, GeneXpert dương tính, có 12 bệnh nhân kháng INH chiếm 21,42\%; có 5 bệnh nhân kháng RMP + INH chiếm $8,93 \%$ và 39 bệnh nhân không kháng, chiếm $69,64 \%$ (Bảng 1). Nguyễn Thị Hậu (2015) [5], nghiên cứu tính kháng thuốc của 31 bệnh nhân lao phổi tái phát cho kết quả có $48,39 \%$ kháng thuốc và có $51,61 \%$ bệnh nhân không có kháng. Trong số các bệnh nhân kháng thuốc, tác giả gặp đơn kháng $53,34 \%$ và đa kháng là $46,66 \%$. Jacobs MG (2020) [6], tiến hành đánh giá đặc điểm kháng thuốc của các vi khuẩn lao ở bệnh nhân lao phổi tái phát có kháng thuốc và cho thấy: đơn kháng gặp 49,1\% và đa kháng gặp 50,9\%. Sự khác biệt giữa các tác giả với nhau và đối với nghiên cứu của chúng tôi có thể do chênh lệch về cõ̃ mẫu cũng như đối tượng nghiên cứu.

4. 2. Mối tương quan giữa tính kháng thuốc với lâm sàng, cận lâm sàng: Khi tìm hiểu mối liên quan giữa tính kháng thuốc của AFB ở các bệnh nhân lao phổi tái phát trong nghiên cứu, chúng tôi thấy các triệu chứng lâm sàng như sốt, khó thở và hang gặp nhiều ở bệnh nhân đơn kháng; trong khi triệu chứng ho gặp nhiều ở nhóm bệnh nhân đa kháng (bảng 2).

Nguyễn Văn Thái (2019) [7] nghiên cứu tính kháng thuốc và mối liên quan với một số đặc điểm lâm sàng, cận lâm sàng và cho thấy, triệu chứng sốt ở nhóm không kháng Rifampicin là $79,17 \%$ bênh nhân và 20,83\% bênh nhân ở nhóm kháng Rifampicin. Các triệu chứng sút cân, ăn kém, ra mồ hôi trộm đều có tỷ lệ cao hơn ở nhóm không kháng Rifampicin so với nhóm kháng Rifampicin. Về các triệu chứng cơ năng thực thể tác giả cũng cho thấy các triệu chưng ho, khạc đờm khó thở đều gặp tỷ lệ cao hơn ở những bệnh nhân lao phổi tái phát không kháng Rifampicin so với nhóm kháng Rifampicin. Kết quả của tác giả cũng tương tự của chúng tôi. Ngoài ra, kết quả điều trị kém thường gặp hơn ở nhóm đơn kháng Isoniazid so với nhóm nhạy cảm với Isoniazid và Rifampicin $(p<0,01)$ khi so sánh với bênh nhân được điều trị thành công. Nhóm đơn kháng Rifampicin có nguy cơ điều trị kém hơn so với nhóm nhạy cảm với Isoniazid và Rifampicin $(p<0,05)$ [7].

Chúng tôi đã tiến hành khảo sát đặc điểm hình ảnh $X$ quang phổi ở các bệnh nhân nghiên cứu và cho thây tổn thương mức độ hẹp ở bệnh nhân lao phổi kháng RMP + INH gặp 50\%, nhiêu hơn nhóm kháng INH (25\%). Mức độ vừa và mức độ rộng chỉ gặp ở nhóm kháng INH, không gặp ở nhóm kháng RMP + INH. Hang lao gặp $100 \%$ ở bệnh nhân kháng RMP + INH, kháng INH gặp 25\% bệnh nhân (Bảng 3). Nguyễn Văn Thái (2019) [7] đã tìm hiểu mối liên quan giữa đặc điểm kháng thuốc với tổn thương trên phim Xquang của bệnh nhân lao phổi tái phát và cho thấy ở bệnh nhân kháng Rifampicin có mức độ tổn thương hẹp là $11,11 \%$, trong khi ở bệnh nhân lao phổi không kháng Rifampicin là $88,89 \%$. Tổn thương mức độ vừa và rộng ở nhóm lao phổi kháng Rifampicin lần lượt là $35,71 \%$ và $35,00 \%$ ít hơn lao phổi không kháng Rifampicin.

Về mối liên quan giữa đặc điểm kháng thuốc với kết quả mức độ AFB đờm cho thấy giữa hai nhóm BN kháng INH và kháng RMP + INH không có sự khác biệt về mối liên guan giữa các mức độ AFB (+) - Bảng 4. Nguyê̂n Văn Thái (2019) [7], tìm hiểu mối liên quan giữa mức độ dương tính AFB trong đờm với đặc điểm kháng thuốc ở bệnh nhân lao phổi tái phát và cho thấy ở nhóm 
lao phổi có kháng Rifampicin có mức độ AFB dương tính $1+$ là $20,83 \%$ và ở nhóm bệnh nhân không kháng Rifampicin là 79,17\%. AFB dương tính 2+ ở nhóm lao phổi có kháng Rifampicin là $40 \%$ ở nhóm lao phổi không kháng Rifampicin là $60 \%$. Mức AFB dương tính 3+ ở nhóm lao phổi có kháng Rifampicin là 33,33\% và ở nhóm lao phổi không kháng Rifampicin là $66,67 \%$. Như vậy kết quả của tác giả cho thấy ở nhóm bênh nhân có kháng Rifampicin có số lương vi khuẩn trong đờm ở các mức độ 1+, 2+, 3+ đều thấp hơn nhóm lao phổi không kháng Rifampicin. Sự khác biệt này có thể do cõ̃ mẫu nghiên cứu khác nhau.

\section{KẾT LUẬN}

Lao đa kháng thuốc ngày càng tăng, mối tương quan lâm sàng, cận lâm sàng với đặc tính kháng thuốc có rất nhiều ý nghĩa cho việc điều trị bệnh.

\section{TÀI LIẸU THAM KHẢO}

1. World Health Organization (2018) Global Tuberculosis report. WHO,
apps.who.int/iris/handle/10665/274453,8-37.
2. Girum T, Muktar E, Lentiro K (2018), Epidemiology of multidrug-resistant tuberculosis (MDR-TB) in Ethiopia: a systematic review and meta-analysis of the prevalence, determinants and treatment outcome".Trop Dis Travel Med Vaccines.4:5. doi: 10.1186/s40794-018-0065-5.

3. Adigun $\mathbf{R}$, Singh $\mathbf{R}(\mathbf{2 0 1 9})$, "Tuberculosis", StatPearls [Internet]. Treasure Island (FL): StatPearls Publishing; 2019 Feb 6.

4. Jamshid Gadoev, Damin Asadov, Anthony D. Harries Recurrent tuberculosis and associated factors: A five - year countrywide study in Uzbekistan (2017), "", PLoS One. 2017; 12(5): e0176473. 10.1371/journal.pone.0176473.

5. Nguyễn Thị Hậu (2015), "Nghiên cứu lâm sàng, cận lâm sàng, tỷ lệ kháng thuốc và kết quả điều trị tẩn công ở bệnh nhân lao phổi tái phát". Luân văn Thạc sỹ, Học viện Quân y, Hà Nội 67tr.

6. Jacobs MG, Pinto Junior VL (2020), "Characterization of drug-resistanttuberculosis in Brazil, 2014", Epidemiol Serv Saude. 2020 Feb 3;28(3):e2018294. doi: 10.5123/S1679

7. Nguyến Văn Thái (2019), "Nghiên cứ tính kháng Rifampicin và môi liên quan giữa một số đăc điểm lâm sàng cận lâm sàng với tính kháng thuốc ở bệnh nhân lao phổi tái phát, Luận văn chuyên khoa 2, Học viện Quân y, Hà Nội72tr.

\section{MộT SỐ YẾU TỐ LIÊN QUAN ĐẾN KẾT QUẢ ĐIỀU TRỊ HORMON TÁI Tổ HỢP Ở TRẺ THIẾU HỤT HORMON TĂNG TRƯỞNG}

\section{TÓM TẮT}

Thiếu hụt hormon tăng trưởng là tình trạng tuyến yên không sản xuất đủ hormon tăng trưởng dấn đến tình trạng lùn ở trẻ em. Tỷ lệ mới mắc dao động $1 / 3500-1 / 4000$. Mục tiêu: Nhận xét một số yếu tố liên quan đến kết quả điều trị hormon tái tổ hợp ở trẻ thiếu hụt hormon tăng trưởng. Đối tượng và phương pháp: 159 bệnh nhân được chẩn đoán và điều trị thiếu hụt hormon tăng trưởng tại Bệnh viện Nhi Trung ương từ tháng 01 năm 2010 đến tháng 06 năm 2019. Nghiên cứu một loạt ca bệnh, đối chứng trước và sau điều trị. Kết quả: trong số 159 bệnh nhân thì nhóm bệnh nhân có nồng độ $\mathrm{GH}$ đỉnh test kích thích $\leq 5 \mathrm{ng} / \mathrm{ml}$ có mối tương quan tuyến tính giữa tốc độ tăng trưởng chiêu $\mathrm{cao}(\mathrm{cm})$ trong năm đầu với nồng độ $\mathrm{GH}$ đỉnh, nồng độ $\mathrm{GH}$ đỉnh càng thấp, tốc đô̂ tăng trưởng càng cao; ngoài ra tuổi bắt đầu điều trị, tuổi xương thời điểm bắt đầu điều trị đều có mối tương quan tuyến tính với tốc độ tăng trưởng chiều cao (SDS, cm) trong năm đâu, điêu trị càng

*Bệnh viện Nhi Trung Uơng

Chịu trách nhiệm chính: Vũ Chí Dũng

Email: dungvu@nch.org.vn

Ngày nhận bài: 28.12.2020

Ngày phản biện khoa họ: 25.01.2021

Ngày duyệt bài: 2.2.2021

\section{Vũ Chí Dũng*, Nguyễn Thị Hằng*}

sớm, tuổi xương càng thấp thì tốc độ tăng trưởng chiều cao năm đâuu càng cao. Kết luận: Bệnh nhân được chẩn đoán và điều trị thiếu hụt hormon tăng trưởng sớm, tuổi xương và nồng độ GH đỉnh test kích thích thấp có đáp ứng tốt hơn với liệu pháp hormon tái tổ hợp thay thế.

Tư khóa: Thiếu hụt hormon tăng trưởng, hormon tăng trưởng tái tổ hợp, lùn ở trẻ em.

\section{SUMMARY}

\section{FACTORS AFFECTING HEIGHT VELOCITY RESPONSE IN rhGH- TREATED CHILDREN WITH GROWTH HORMONE DEFICIENCY}

Growth hormone deficiency is a condition that occurs when the pituitary gland does not produce enough growth hormone. This is the most common endocrine cause in short status which incidence is between $1 / 3500-1 / 4000$. Objective: to study factors affecting the height velocity response in $\mathrm{rhGH}$ treated children with growth hormone deficiency. Patiens and Method: A case series study and comparing before and after treatment with rhGH, 159 patients with growth hormone deficiency was evaluated at National Children's Hospital from 1/2010 to 6/2019. Results: A significantly negative correlation was seen between first year change in height (cm, SDS) and bone age, chronological age at initiation of treatmen while a significantly negative 